\title{
Avaliação de lente intra-ocular fácica para a correção da presbiopia
}

\author{
Phakic intraocularlens for presbyopia correction
}

\author{
Caroline Amaral Ferraz ${ }^{1}$ \\ Norma Allemann ${ }^{2}$ \\ Wallace Chamon $^{3}$
}

Trabalho realizado no Departamento de Oftalmologia Universidade Federal de São Paulo - UNIFESP - São Paulo (SP) - Brasil.

${ }^{1}$ Doutora em Oftalmologia do Departamento de Oftalmologia da Universidade Federal de São Paulo - UNIFESP - São Paulo (SP) - Brasil.

${ }^{2}$ Professora, Doutora em Oftalmologia do Departamento de Oftalmologia da UNIFESP - São Paulo (SP) - Brasil. ${ }^{3}$ Livre Docente, Professor Adjunto do Departamento de Oftalmologia da UNIFESP - São Paulo (SP) - Brasil.

Endereço para correspondência: Rua Loefgreen, 1587/14 São Paulo (SP) CEP 04040-032

E-mail: carolferraz@oftalmo.epm.br

Recebido para publicação em 25.01.2007

Última versão recebida em 29.04.2007

Aprovação em 04.05.2007

Nota Editorial: Depois de concluída a análise do artigo sob sigilo editorial e com a anuência dos Drs. Marcelo Carvalho da Cunha e Marcelo Vieira Neto sobre a divulgação de seus nomes como revisores, agradecemos suas participações neste processo.

\begin{tabular}{l} 
RESUMO \\
\hline Objetivos: Avaliar os resultados clínicos e refrativos, bem como as \\
complicações pós-operatórias, da cirurgia de implante de uma lente \\
fácica multifocal de suporte angular para a correção da presbiopia. \\
Métodos: Estudo retrospectivo de análise de prontuários de 30 pacien- \\
tes dos quais 51 olhos foram submetidos a implante de lente intra-ocular \\
fácica Newlife ${ }^{\circledR}$ para a correção da presbiopia. Os pacientes foram \\
avaliados em visita pré-operatória e em um mês, 3, 6 e 12 meses após a \\
cirurgia. A análise descritiva das variáveis do estudo e os testes esta- \\
tísticos foram realizados e as complicações pós-operatórias foram \\
descritas. Resultados: Após o procedimento, o equivalente esférico \\
médio foi de -0,046 ( $\pm 0,48$ D) e $87,5 \%$ dos pacientes podiam ler P3 \\
(equivalente a J2) sem necessidade de óculos. A perda de células \\
endoteliais, após seguimento de 12 meses, foi de $7,57 \%$. A lente intra- \\
ocular foi retirada em 6 (11,5\%) olhos por diferentes razões, sendo a \\
catarata a causa mais freqüente de retirada de lente. Conclusões: O \\
implante da lente intra-ocular fácica Newlife ${ }^{\circledR}$ para a correção da \\
presbiopia melhorou significativamente a acuidade visual sem corre- \\
ção e a refratometria no grupo de olhos estudados. Os critérios de \\
avaliação adotados (acuidade visual com correção, contagem endotelial \\
e existência de complicações) não permitiram afirmar a segurança do \\
procedimento de implante da lente intra-ocular fácica Newlife ${ }^{\circledR}$ para o \\
período de acompanhamento analisado. \\
\hline
\end{tabular}

Descritores: Presbiopia/cirurgia; Implante de lente intra-ocular; Complicações pósoperatórias; Estudos retrospectivos

\section{INTRODUÇÂO}

Os avanços no desenho e material das lentes intra-oculares, juntamente com as modificações nas técnicas cirúrgicas e o maior entendimento da fisiologia do endotélio da córnea renovaram o interesse na cirurgia de implante de lentes fácicas ${ }^{(1)}$.

As lentes intra-oculares fácicas de suporte angular mostraram eficácia para a correção da alta miopia ${ }^{(2)}$. Os modelos mais recentes de lentes intraoculares fácicas parecem demonstrar maior segurança quanto à perda de células do endotélio da córnea, além disso as vantagens como a reversibilidade do procedimento já foram relatadas por diversos autores ${ }^{(3-6)}$.

A população présbita é o grupo demográfico com o crescimento mais rápido que existe, mas a correção cirúrgica da presbiopia continua sendo um desafio para cirurgia refrativa moderna.

Em 1997, a agência americana Food and Drug Administration (FDA) aprovou o implante da primeira lente intra-ocular multifocal após extração 
da catarata $^{(7)}$. O uso das lentes multifocais tem sido relatado como satisfatório, muito embora exista associação entre a multifocalidade e o aumento da incidência de efeitos adversos como visão de halos $^{(8)}$.

Considerando que a maioria dos pacientes que desejam a cirurgia para a correção da presbiopia ainda não necessita da extração do cristalino, a idéia de uma lente intra-ocular fácica multifocal seria uma alternativa para pacientes présbitas jovens.

O objetivo deste estudo é avaliar os resultados clínicos e refrativos, bem como as complicações pós-operatórias, da cirurgia de implante de uma lente fácica multifocal de suporte angular para a correção da presbiopia.

\section{MÉTODOS}

\section{Desenho do estudo}

\section{Estudo retrospectivo de análise de prontuários.}

O estudo foi aprovado pelo Comitê de Ética em Pesquisa da Escola Paulista de Medicina - Universidade Federal de São Paulo, sob o parecer 77/2004 (Anexo 1).

\section{Seleção de pacientes}

Os pacientes submetidos ao implante da lente fácica para a correção da presbiopia foram selecionados conforme os seguintes critérios:

\section{Critérios de inclusão}

a) motivados para cirurgia refrativa para a correção da presbiopia;

b) refração para longe entre $+5,00$ e - 5,00 dioptrias;

c) présbitas com necessidade de adição maior que 1,50 dioptrias;

d) segmento anterior normal ao exame de biomocroscopia;

e) oftalmoscopia indireta sem sinais de lesões predisponentes de descolamento de retina;

f) profundidade de câmara anterior maior que 3,00 mm medida no IOLMaster;

g) ângulo irido-corneano normal (gonioscopia normal, pigmentação ausente) e ângulo de grau $1 \mathrm{~V}$ pelo método de graduação de Shaeffer;

h) contagem endotelial superior a 2000 células $/ \mathrm{mm}^{2}$;

i) videoceratografia computadorizada com padrão regular e simétrico;

j) entendimento do procedimento cirúrgico, de suas limitações e possíveis complicações, da necessidade de acompanhamento e a anuência aos itens descritos no termo de consentimento;

k) ausência do uso de drogas sistêmicas imunossupressoras ou de efeito psicotrópico.

\section{Critérios de exclusão}

Foram excluídos deste estudo pacientes que não se encaixavam nos critérios ora citados e aqueles portadores de doenças sistêmicas como: diabetes, doenças do colágeno e infectocontagiosas. Foram excluídos também, pacientes submetidos à cirurgia ocular prévia, portadores de uveíte, qualquer tipo de distrofia corneana, retinopatia ou maculopatia, catarata e hipertensão ocular (pressão intra-ocular acima de $20 \mathrm{mmHg}$ ).

A rotina pré e pós-operatória consistiu de anamnese e exame ocular completo, incluindo acuidade visual com e sem correção, exame de refratometria objetiva e subjetiva, biomicroscopia à lâmpada de fenda, tonometria de aplanação, ceratometria, videoceratografia computadorizada, mensuração do diâmetro da câmara anterior com base na medida de branco-abranco obtida a partir de imagens capturadas no topógrafo, microscopia especular, paquimetria, gonioscopia, análise da profundidade da câmara anterior e oftalmoscopia indireta.

A contagem endotelial foi realizada com um microscópio especular de não contato, modelo SP 8000 (Konan, Japão). Realizou-se a captação da imagem correspondente à área central da córnea e, a partir deste campo, foram determinadas a densidade (análise quantitativa) e a morfologia (análise qualitativa) das células endoteliais.

Para análise quantitativa foram realizadas cinco contagens e em cada uma destas contagens foram marcadas 30 células de cada fotografia. A média dos cinco valores obtidos foi utilizada como valor da contagem endotelial.

\section{O implante intra-ocular}

A parte óptica era composta de material acrílico com $38 \%$ de hidratação e seu diâmetro era de $5,5 \mathrm{~mm}$, dividido em três zonas: visão de longe (no centro), visão de perto (na média periferia) e outra zona de visão de longe (na periferia). $\mathrm{O}$ diâmetro da zona central era 1,5 mm e a largura do anel da zona intermediária era $1,1 \mathrm{~mm}$.

O háptico era de estrutura rígida, angulada com três pontos de apoio, e composto de polimetilmetacrilato (PMMA) com extremidade acrílica hidrofílica nestes três pontos.

A disponibilidade do diâmetro total da lente bifocal era 12, 12,5 e 13 milímetros. A disponibilidade do poder dióptrico variava de $-5,00$ a $+5,00$ dioptrias para visão de longe. A única adição disponível neste tipo de implante foi de $+2,5$ dioptrias esféricas.

O poder dióptrico da lente fácica a ser implantada em cada olho foi calculado com base na fórmula refrativa de Holladay que leva em consideração a refração do paciente na distância vértice dos óculos, a ceratometria, e a profundidade da câmara anterior $^{(9)}$. Este seria o poder dióptrico da LIO para longe.

Como a lente apresentava uma única possibilidade de adição de 2,50 dioptrias, esta foi a única adição usada em todos os pacientes.

A distância de branco-a-branco do diâmetro da câmara anterior foi obtida com base nas imagens fotográficas capturadas pela topografia, utilizadas para a determinação do diâmetro total da lente intra-ocular fácica que deveria ser colocada. Para a escolha do diâmetro ideal acrescentou-se $0,5 \mathrm{~mm}$ à medida branco-a-branco e comparou-se com a medida intra-operatória realizada com o medidor plástico. Quando houve divergência de valores, a medida intra-operatória foi considerada para a escolha da lente ideal. 


\section{Técnica cirúrgica}

Todas as cirurgias foram realizadas pelo mesmo cirurgião (GB). A miose operatória, imperativa, foi realizada meia hora antes do procedimento cirúrgico com a instilação de uma gota de colírio de cloridrato de pilocarpina a $2 \%$.

No ato cirúrgico, após assepsia e colocação de campos estéreis, foi realizada uma incisão na córnea no meridiano das 12 horas com bisturi descartável de 3,2 mm de diâmetro, seguida de injeção de substância viscoelástica (Viscoat, Alcon) para preenchimento da câmara anterior. Em seguida, duas paracenteses laterais nas posições de 3 e 9 horas foram realizadas com bisturi descartável de angulação $22,5^{\circ}$ com o objetivo de facilitar a manobra de posicionamento da lente.

Em todos os casos foi utilizado um medidor plástico graduado que foi inserido na câmara anterior já aberta e preenchida de viscoelástico para confirmar as medidas prévias do diâmetro interno da câmara anterior. Este medidor foi introduzido com a ajuda de uma pinça a partir da incisão na posição de 12 horas e delicadamente empurrado até o limite do ângulo da câmara anterior na posição de 6 horas. A mensuração foi realizada quando o medidor encontrava-se perpendicular ao eixo do microscópio e a pupila estava perfeitamente redonda, sendo usado como referência o centro da pupila (Figura 1).

Uma vez escolhido o diâmetro adequado, a lente intraocular foi dobrada com o auxílio de duas pinças para facilitar sua inserção na câmara anterior.

A alça distal bípode foi inserida pela incisão principal com o auxílio de uma pinça, seguida da parte óptica dobrada e por último foi inserida a alça proximal. A figura $8 \mathrm{C}$ mostra a posição da alça distal direcionada para o ângulo da câmara anterior oposto à incisão de entrada. Normalmente os apoios das alças ficavam nas posições de 5 e 7 horas.

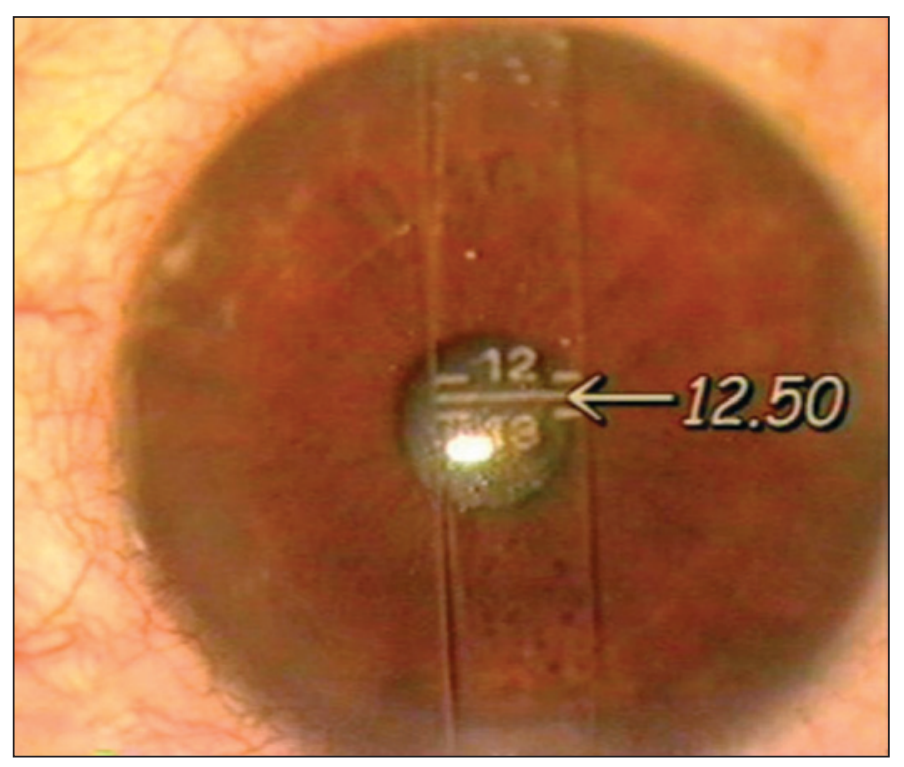

Figura 1 - Fotografia mostrando o medidor plástico para aferição do diâmetro interno da câmara anterior no intra-operatório. Observar que a pupila apresenta-se perfeitamente redonda.
A segunda alça era posicionada no ângulo sob a incisão com o auxílio de um gancho. Uma vez posicionada na câmara anterior, a estabilidade da lente intra-ocular e a modificação da forma da pupila eram verificadas. Quando necessária, realizava-se a rotação da lente.

A substância viscoelástica era retirada com cânula de irrigação-aspiração e a câmara anterior era preenchida com solução salina balanceada. Após o teste da incisão auto-selante, nenhum tipo de sutura foi necessário.

Vinte e quatro horas depois da cirurgia, o curativo foi retirado e o uso de acetazolamida $400 \mathrm{mg}$ via oral (Diamox ${ }^{\circledR}$, Aventis) foi prescrito por um dia.

\section{Coleta de dados e análise}

Os dados foram coletados retrospectivamente dos prontuários de pacientes que tinham se submetido ao implante da lente multifocal fácica.

Todos os pacientes foram examinados no primeiro e sétimo dia pós-operatório e em seguida em um mês, três, seis e doze meses após a cirurgia e a seguir anualmente.

Os retornos de um e sete dias para tonometria e avaliação de segmento anterior não foram considerados para análise.

O exame pós-operatório consistia de avaliação da visão corrigida e não corrigida para longe e perto, aspecto à biomicroscopia do segmento anterior, avaliação da forma da pupila, medida da pressão intra-ocular, contagem endotelial, gonioscopia e avaliação subjetiva das queixas dos pacientes.

As variáveis estudadas foram: acuidade visual para longe e para perto sem correção e com correção, equivalente esférico e contagem de células endoteliais.

Os dados de análise pré-operatória e de pós-operatório de 1 ano foram avaliados utilizando o programa SPSS 13.0. Os resultados foram descritos em médias e em desvio-padrão. Os valores de acuidade visual de Snellen foram convertidos em $\log$ MAR para análise estatística.

Todas as variáveis estudadas foram testadas quanto à normalidade de suas distribuições pelo teste de KolmogorovSmirnov. As variáveis que seguiram a distribuição normal foram analisadas por testes paramétricos e as que não seguiram foram analisadas por testes não-paramétricos.

Assim, para se analisar o comportamento das variáveis ao longo dos tempos estudados (pré-operatório, pós-operatório de um mês, três, seis, doze meses), dois testes foram utilizados: análise de variância de medidas repetidas (General Linear Model - GLM), como teste paramétrico e o teste de Friedman (análise de variância de medidas repetidas ou blocos randômicos) como teste não-paramétrico.

Todas estas análises foram seguidas por testes de comparações múltiplas. No caso de dados paramétricos foi usado o teste de Tukey-Kramer, recomendado devido ao grande número de comparações duas a duas realizadas. No caso de não paramétricos foi utilizado o teste de Dunn.

As análises dos tempos estudados para variáveis que não seguiram a distribuição normal foram realizadas pelo teste não 
paramétrico de Friedman (medidas repetidas), seguido do teste de comparações múltiplas de Dunn.

\section{RESULTADOS}

A amostra foi constituída de 51 olhos de 30 indivíduos, sendo 17 olhos pertencentes a 10 homens $(33,33 \%$ do total de pacientes) e 34 olhos pertencentes a 20 mulheres $(66,66 \%$ do total de pacientes).

A média de idade dos pacientes foi de $54,88 \pm 5,99$. Não houve diferença significante entre a idade dos homens e a das mulheres $(\mathrm{t}=0,049 ; \mathrm{P}=0,961)$. No pré-operatório 45 olhos $(88 \%)$ eram hipermétropes e 6 olhos $(12 \%)$ eram míopes. A média do equivalente esférico pré-operatório foi $+1,46 \mathrm{D} \pm 1,82 \mathrm{SD}$ (-4,00 D a +5,00 D). A média de contagem de células endoteliais pré-operatória foi de $2574 \pm 216$ cells $/ \mathrm{mm}^{2}$ (2112 to 3006 cells $\left./ \mathrm{mm}^{2}\right)$ e a ceratometria média foi $43,63 \pm 1,69 \mathrm{D}$ (40,8 to 46,37 D).

\section{Acuidade Visual}

\section{Acuidade Visual para longe}

A média da acuidade visual para longe mostrou diferença estatisticamente significante entre a visita pré-operatória (0,552 logMAR) e a visita de 1 mês pós-operatória $(0,195 \log$ MAR). Não houve diferença estatisticamente significante entre as visitas pós-operatórias entre si, mostrando estabilidade nos resultados pós-cirúrgicos. Entretanto, houve perda de linhas de acuidade visual corrigida em 6 olhos. Cinco olhos perderam uma linha e 1 olho perdeu 2 linhas (Figura 2).

\section{Acuidade Visual para perto}

A média da acuidade visual para perto mostrou diferença estatisticamente significante entre o período pré-operatório e todas as visitas pós-operatórias (teste de Friedman). Não houve diferença nos valores médios de acuidade visual para perto corrigida (teste de comparações múltiplas de Dunn). A maioria dos olhos $(87,5 \%)$ eram capazes de ler Parinaud 3 ou melhor (equivalente a Jaeger 2 ou melhor) sem a necessidade de óculos na visita de seguimento de 12 meses (Figura 3).

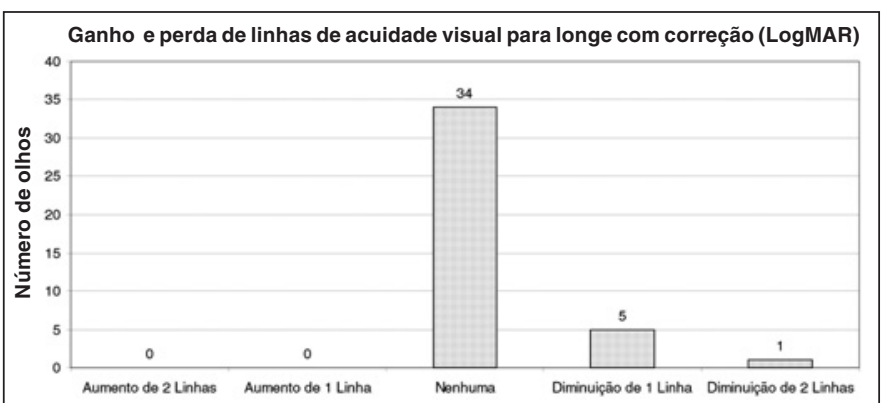

Figura 2 - Avaliação de ganho e perda de linhas de acuidade visual para longe sem correção na visita pós-operatória de 12 meses em relação ao pré-operatório em olhos submetidos ao implante da LIO fácica para a correção da presbiopia

\section{Equivalente esférico}

Após o implante da lente intra-ocular, a média do equivalente esférico foi de $-0,05 \pm 0,44 \mathrm{D}(-1,25$ a 1,25 D). A evolução do equivalente esférico ao longo do tempo é mostrada na figura 4. Em 12 meses de seguimento pós-operatório a porcentagem de olhos com equivalente esférico diferindo apenas $0,5 \mathrm{D}$ da emetropia foi de $75 \%$.

\section{Complicações}

A ovalização pupilar foi observada no período pós-operatório em 12 olhos (25\%). O critério utilizado para definir ovalização pupilar foi a diferença maior que $0,5 \mathrm{~mm}$ entre os diâmetros horizontal e vertical da pupila (Figura 5).

Relatos subjetivos da visão de halos foram descritos em 17 olhos $(31,3 \%)$.

A rotação da lente intra-ocular foi observada em quatro olhos devido a inadequação de tamanho. O manejo das lentes que rodaram foi reposicionamento do implante em dois olhos, troca da lente intra-ocular em outro olho e retirada definitiva da lente no último olho por queixa de diplopia insuportável.

Seis lentes fácicas intra-oculares (11\%) precisaram ser retiradas por diferentes razões. Três lentes foram retiradas por

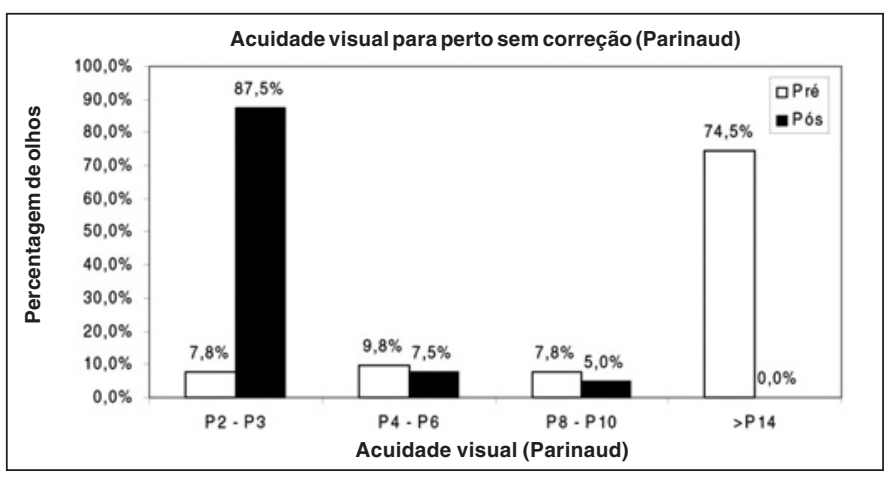

Figura 3 - Distribuição dos percentuais da acuidade visual para perto sem correção nas visitas pré-operatória e pós-operatória de 12 meses em olhos submetidos ao implante da LIO fácica para a correção da presbiopia

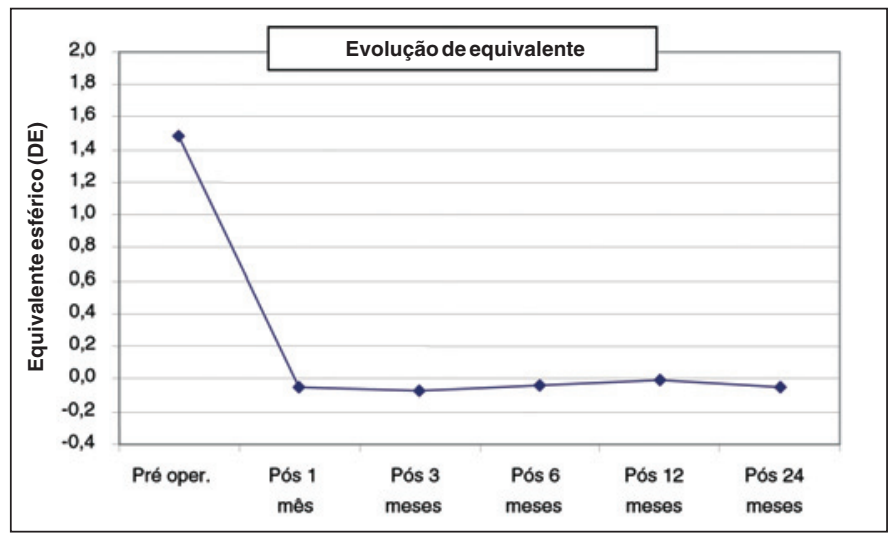

Figura 4 - Distribuição das médias do equivalente esférico (DE), nas seis visitas estudadas, em olhos submetidos ao implante da LIO fácica para a correção da presbiopia 


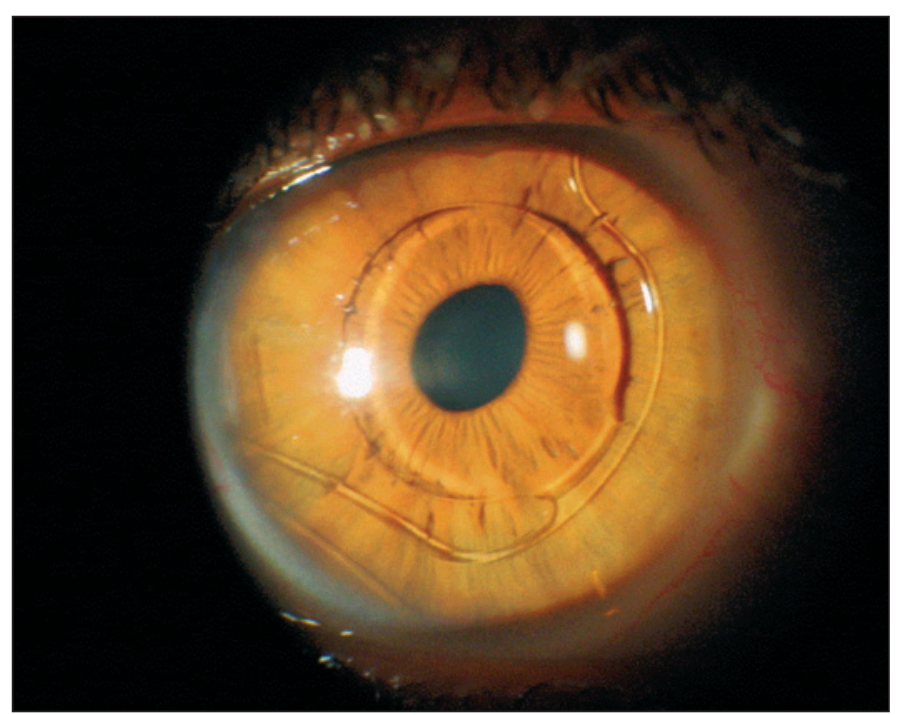

Figura 5 - Retração pupilar em olho submetido ao implante da lente intra-ocular fácica para a correção da presbiopia em fotografia de lâmpada de fenda. Observa-se o estiramento da pupila no eixo de apoio das alças da lente intra-ocular. As medidas da pupila neste caso foram $4,0 \mathrm{~mm}$ no eixo de maior diâmetro e de $3,5 \mathrm{~mm}$ no eixo de menor diâmetro com diferença de $0,5 \mathrm{~mm}$.

catarata. Os outros motivos de retirada de lente foram: insatisfação com visão intermediária, erro refrativo residual e diplopia.

Quanto à contagem de células endoteliais, houve uma diferença estatisticamente significante entre o valor pré-operatório $\left(2574,5 \pm 216\right.$ células $\left./ \mathrm{mm}^{2}\right)$ e os valores pós-operatórios de 12 meses $\left(2379 \pm 269\right.$ células $/ \mathrm{mm}^{2}$ ). Houve diferença significante entre as visitas pós-operatórias na comparação pós-operatório de um mês com o pós-operatório de 12 meses (Tukey-Kramer $\mathrm{p}<0,001$ ) indicando a continuidade da perda celular. A perda endotelial acumulada em 1 ano foi de 7,57\%.

\section{DISCUSSÃO}

A correção cirúrgica da presbiopia é a nova fronteira da cirurgia refrativa ${ }^{(10)}$. Novos modelos de lentes multifocais intra-oculares estão disponíveis e poucos estudos relatam os resultados de lentes fácicas multifocais para a correção da presbiopia $^{(11-12)}$.

De uma maneira geral, os resultados apresentados no presente estudo concordam com os relatos previamente publicados sobre resultados refrativos com cirurgia de implante de lentes fácicas ${ }^{(2-3,6,12)}$. Houve previsibilidade no que se refere ao equivalente esférico e houve melhora nos valores médios de acuidade visual para longe e para perto sem correção. Mesmo tendo-se relatado a perda de linha de acuidade visual em $11 \%$ (6/51) dos olhos, com a média de acuidade visual sem correção melhorou significantemente tanto para longe como para perto.

Não houve estabilidade na contagem de células endoteliais ao longo do período de acompanhamento e a perda acumulada de células endoteliais nos pacientes submetidos ao implante da lente fácica para a correção da presbiopia foi maior no presente estudo do que nos outros estudos publicados na literatura ${ }^{(13-15)}$. Além disso, o índice de retirada da lente intraocular também foi maior que previamente descrito ${ }^{(11)}$. A maior causa da retirada da lente foi a catarata ( 3 de 51 olhos apresentaram catarata).

A inflamação crônica subclínica poderia ser a razão para a cataratogênese, mas o estudo não se propõe a responder esta afirmação. Os olhos que apresentaram catarata pertenciam a pacientes hipermetrópes.

Os outros efeitos indesejados observados após a cirurgia de implante de lente intra-ocular para a correção da presbiopia ocorreram devido à inadequação de escolha do tamanho do diâmetro da lente. Mesmo havendo a possibilidade de escolha de três diferentes diâmetros (12, 12,5 e 13 mm), a correta mensuração do diâmetro da câmara anterior é ainda um desafio. A maioria das complicações encontradas como a ovalização pupilar, a rotação da lente, a queixa de diplopia e as queixas subjetivas da visão de halos relacionam-se à escolha do diâmetro inadequado da lente. Novos aparelhos de medidas utilizando novas tecnologias parecem estar mais acurados nas mensurações da biometria da câmara anterior ${ }^{(16-17)}$, mas novos estudos são necessários para sua validação.

Concluindo, o interesse no uso de lentes fácicas multifocais é a possibilidade de permitir uma alternativa de correção cirúrgica em pacientes présbitas sem a necessidade de extração de cristalino.

Observamos que houve previsibilidade, mas não foi possível afirmar a segurança do procedimento estudado.

Com a avaliação das complicações e das causas que levaram à retirada da lente intra-ocular fácica multifocal para a correção da presbiopia, pode-se perceber a relevância da seleção criteriosa dos pacientes no período pré-operatório. Além disso, este estudo retrospectivo atentou para a relativa dificuldade de determinação do correto diâmetro interno da câmara anterior e escolha adequada do diâmetro da lente fácica.

A avaliação de células endoteliais em cirurgia com implante de lente intra-ocular fácica deve ser criteriosa e continuada para detecção precoce de alterações qualitativas e quantitativas. O acompanhamento em longo prazo é mandatório e o estudo deverá continuar.

\section{AGRADECIMENTOS}

Agradecemos ao Dr. Georges Baikoff a realização das cirurgias

\section{ABSTRACT}

Purpose: To evaluate clinical and refractive results of anterior chamber multifocal phakic intraocular lens Newlife ${ }^{\circledR}$ for presbyopia correction considering uncorrected far and near visual acuity and refraction data and also to evaluate safety of this intraocular lens considering distance and near corrected visual acuity, endothelial cell count and complica- 
tions. Methods: Retrospective analysis of a clinical database of 30 patients (51 eyes) who had received a foldable anterior chamber multifocal intraocular lens for presbyopia correction. Data were collected before surgery and at 1, 3, 6, 12 months after the procedure. Statistical variance analysis and multiple comparisons were used to verify possible associations. All complications were described. Results: After surgery the mean spherical equivalent was $-0.046 \mathrm{D}(+/-0.48)$ and $87.5 \%$ of the eyes could read Parinaud 3 or better (equivalent to $\mathrm{J} 2$ or better) without the need of near glasses. Endothelial cell loss was $7.57 \%$. The intraocular lens was explanted in $6(11.5 \%)$ eyes for different reasons. Cataracts were the major cause of lens removal. Conclusion: Improvement of mean uncorrected visual acuity and refraction data after multifocal phakic intraocular lens Newlife ${ }^{\circledR}$ implantation for presbyopia correction was observed. Established safety criteria (distance and near corrected visual acuity, endothelial cell count and complications) did not confirm the safety of the procedure in the follow-up period.

Keywords: Presbyopia/surgery; Lens implantation, intraocular; Postoperative complications; Retrospective studies

\section{REFERÊNCIAS}

1. Alio JL. Advances in phakic intraocular lenses: indications, efficacy, safety, and new designs. Curr Opin Ophthalmol. 2004;15(4):350-7.

2. Allemann N, Chamon W, Tanaka HM, Mori ES, Campos M, Schor P, Baïkoff G. Myopic angle-supported intraocular lenses: two-year follow-up. Ophthalmology. 2000;107(8):1549-54.

3. Alió JL, Kelman C. The Duet-Kelman lens: A new exchangeable anglesupported phakic intraocular lens. J Refract Surg. 2003;19(5):488-95.
4. Auffarth GU. Phakic intraocular lenses. Ophthalmologe. 2004;101(3):229-31. Id: Ger.

5. Leccisotti A. Bioptics by angle-supported phakic lenses and photorefractive keratectomy. Eur J Ophthalmol. 2005;15(1):1-7.

6. Olson RJ, Werner L, Mamalis N, Cionni R. New intraocular lens technology. Am J Ophthalmol. 2005;140(4):709-16.

7. Javitt JC, Steinert RF. Cataract extraction with multifocal intraocular lens implantation: a multinational clinical trial evaluating clinical, functional, and quality-of-life outcomes. Ophthalmology. 2000;107(11):2040-8.

8. Nijkamp MD, Dolders MG, de Brabander J, van den Borne B, Hendrikse F, Nuijts RM. Effectiveness of multifocal intraocular lenses to correct presbyopia after cataract surgery: a randomized controlled trial. Ophthalmology. 2004; 111(10):1832-9. Erratum in: Ophthalmology. 2004;111(11):2022.

9. Holladay JT. Refractive power calculations for intraocular lenses in the phakic eye. Am J Ophthalmol. 1993;116(1):63-6.

10. Baikoff G. Surgical treatment of presbyopia: scleral, corneal, and lenticular. Curr Opin Ophthalmol. 2004;15(4):365-9.

11. Baikoff G, Matach G, Fontaine A, Ferraz C, Spera C. Correction of presbyopia with refractive multifocal phakic intraocular lenses. J Cataract Refract Surg. 2004;30(7):1454-60. Comment in: J Cataract Refract Surg. 2005;31(7):1266; author reply 1266 .

12. Alió JL, Mulet ME. Presbyopia correction with an anterior chamber phakic multifocal intraocular lens. Ophthalmology. 2005;112(8):1368-74.

13. Pérez-Santonja JJ, Iradier MT, Sanz-Iglesias L, Serrano JM, Zato MA. Endothelial changes in phakic eyes with anterior chamber intraocular lenses to correct high myopia. J Cataract Refract Surg. 1996;22(8):1017-22.

14. Javaloy J, Javaloy T, Borras F, Vidal MT, Mulet E, Belda JI, Alió J. Safety of iris claw phakic intraocular lenses: An endothelial microscopy long term study [abstract]. Invest Ophthalmol Vis Sci. 2004;45: E-Abstract 337.

15. Alió JL, de la Hoz F, Pérez-Santonja JJ, Ruiz-Moreno JM, Quesada JA Phakic anterior chamber lenses for the correction of myopia: a 7-year cumulative analysis of complications in 263 cases. Ophthalmology. 1999; 106(3): 458-66. Comment in: Ophthalmology. 1999;106(11):2041-3.

16. Baikoff G, Lutun E, Ferraz C, Wei J. Static and dynamic analysis of the anterior segment with optical coherence tomography. J Cataract Refract Surg. 2004;30(9):1843-50.

17. Goldsmith JA, Li Y, Chalita MR, Wetphal V, Patil CA, Rollins AM, et al. Anterior chamber width measurement by high-speed optical coherence tomography. Ophthalmology. 2005;112(2):238-44. Comment in: Ophthalmology. 2005;112(9):1638-9. 